\title{
Behavior and Practices of Type 2 Diabetic Patients Regarding Obesity: A Cross-Sectional Study
}

Quratulain Akbar ${ }^{1}$, Bilal Ahmed Khan ${ }^{1}$, Bakhtawar Saleem Rajput ${ }^{1}$, Nadia Nazir Jatoi ${ }^{1}$, Sadia Elahi ${ }^{1}$, Abbas Mustafa Gain ${ }^{1}$, Arooba Amjad ${ }^{1}$, Dureshahwar Akbar ${ }^{1}$, Maaz Bin Nazir ${ }^{1}$, Naveed Gianchand ${ }^{1}$

1. Internal Medicine, Dow Medical College, Dow University of Health Sciences, Karachi, PAK

Corresponding author: Bilal Ahmed Khan, ronaldorooneyberbatov@gmail.com

\section{Abstract \\ Background}

Obesity is a major public health concern and is associated with incident cardiovascular diseases. A very few studies around the globe have assessed how type 2 diabetic (T2D) patients comprehend obesity. Our study aims to evaluate the concerns and behaviors of T2D patients regarding obesity in a developing country like Pakistan.

\section{Methods}

A cross-sectional study was conducted in Karachi during the period of December to February 2020 in which T2D patients were assessed for their comprehension of how obesity affects their disease and concerns, as well as their practices such as weight loss activities and dietary habits. Data analysis was performed using Statistical Package for the Social Sciences Version 24 (IBM Corp., Armonk, NY, USA).

\section{Results}

Of 417 T2D patients inducted in our study, 265 (63.5\%) knew their ideal body weight, whereas only 221 (52.9\%) knew how to measure it. Among those who were willing to lose weight, this was mostly due to a wish to avoid further complications of obesity ( $\mathrm{N}=155$ [73.1\%]) and also peer/family pressures ( $\mathrm{N}=124$ [58.5\%]) among other reasons. More obese $(\mathrm{N}=68$ [43.6\%]) than non-obese participants ( $\mathrm{N}=87$ [33.3\%]) were willing to consult a doctor to help them reduce weight. Participants had adopted various strategies to reduce weight, of which increasing exercise $(\mathrm{N}=242$ [85.8\%]) and healthy eating $(\mathrm{N}=162$ [57.4\%]) were most popular.

\section{Conclusions}

There is a need to address barriers to weight loss among T2D patients in Pakistan and to provide patients with pragmatic guidelines on how to make sustainable lifestyle changes to help reduce and maintain their body weight.

Received 08/21/2020

Review began 08/25/2020 Review ended 08/25/2020 Published 08/30/2020

\section{(c) Copyright 2020}

Akbar et al. This is an open access article distributed under the terms of the Creative Commons Attribution License CC-BY 4.0., which permits unrestricted use, distribution, and reproduction in any medium, provided the original author and source are credited.
Categories: Endocrinology/Diabetes/Metabolism, Internal Medicine, Public Health

Keywords: type 2 diabetes, obesity, diabetes mellitus, diabetes complications, health behavior

\section{Introduction}

The World Health Organization (WHO) has labeled obesity a global epidemic. Obesity is classified as a body mass index (BMI) of $\geqslant 30 \mathrm{~kg} / \mathrm{m} 2$ and is a major risk factor for insulin resistance leading to type 2 diabetes mellitus (T2DM) [1]. Many epidemiological studies support an association between T2DM and obesity [2,3].

According to the WHO, the prevalence of T2DM in Pakistan for the year 2000 was 5.2 million, and for 2030, it is estimated to be 13.8 million. One-fourth of the population of Pakistan can be categorized as overweight or obese with the use of Indo-Asian-specific BMI cutoff values [4]. Developing or transitional economies are experiencing globalization of food markets, growing fast-food chains, and a rising trend of street vendors providing food items at affordable prices [5]. This is also the case for Pakistan, especially in urban areas, making this population susceptible to obesity and its associated complications.

Obesity and T2DM together are associated with significant morbidity and mortality due to cardiovascular disease [6]. Numerous measurements of obesity, with BMI, waist circumference, waist-to-hip ratio, and waist-to-stature ratio, are associated with the risk of T2DM [7]. In obese patients with T2DM, weight loss has a positive impact on the control of hyperglycemia [8]. Patient enthusiasm and knowledge are important factors in the management of both obesity and T2DM, and it is therefore important to evaluate the behavior and practices of T2DM patients with regard to obesity and related disorders. 
There is a paucity of literature on this topic from developing countries such as Pakistan. The aim of this study is to evaluate the behavior and practices of type 2 diabetic (T2D) patients regarding obesity in Karachi, Pakistan.

\section{Materials And Methods}

A cross-sectional, population-based study was conducted in two tertiary care hospitals of Karachi (Civil Hospital and Pakistan Steel Hospital) during the period of December to February 2020 after getting approval from the Institutional Review Board of Dow University of Health Sciences. The sample population consisted of T2DM patients selected through convenience sampling. A sample size of 450 was taken through openepi.com with a 97\% confidence level. Out of this, 417 completed the questionnaire fully, yielding a cooperation rate of $92.9 \%$. Only residents of Karachi who were suffering from T2DM were included in this study. Patients with type $1 \mathrm{DM}$ and gestational DM were excluded.

A structured questionnaire was used to carry out data collection. The questionnaire was available in both English and Urdu (the national language of Pakistan) to reduce linguistic barriers. Before data collection was started, the questionnaire was reviewed for relevance and completeness by two physicians independently, and a pilot study was also conducted and relevant changes were made. The questionnaire was divided into four sections containing 29 questions. The first section of the questionnaire consisted of sociodemographic information such as age, gender, weight, height, and level of education, as well as personal and family history of present medical illness. The second section dealt with comprehension regarding obesity, ideal body weight, BMI thresholds, and risk factors/causes of obesity. The third section assessed the behavior of the participants concerning obesity with coexisting T2DM and their willingness to lose weight, make dietary changes, and adopt exercise. The final section inquired about their weight loss regime (if any), dietary habits, and practices such as measurement of weight, blood pressure, and blood glucose level. Only recent and relevant information was asked in the questionnaire in order to minimize recall bias.

Verbal or written consent was taken from all participants after assuring them of complete confidentiality. The study investigators verbally interviewed those participants who were illiterate and completed the questionnaire on their behalf based on their oral responses. Interviewer bias was reduced here by training all interviewers to approach and interact with participants in a neutral and non-judgmental manner prior to carrying out data collection. No imputation method was used to account for missing data; incomplete questionnaires were excluded from the analysis.

T2DM was defined by the WHO definition, i.e., maintained fasting blood glucose of $\geqslant 7.0 \mathrm{mmol} / \mathrm{L}$ [9]. Respondents were categorized as obese $(\mathrm{BMI} \geqslant 30)$ or non-obese $(\mathrm{BMI}<30)$ per the WHO criteria. Data were analyzed using Statistical Package for the Social Sciences (SPSS) Version 24.0 (IBM Corp., Armonk, NY, USA).

\section{Results}

Of the 417 T2D patients who participated in this study, 156 (37.4\%) were obese. A majority of participants had a family history of either hypertension $(n=262$ [62.8\%]) or T2DM $(n=246$ [60.0\%]). The baseline characteristics of the study population are summarized in Table 1. 


\section{Cureus}

\begin{tabular}{|l|l|l|}
\hline \multicolumn{1}{|l|}{} & Male & Female \\
\hline Gender & $200(49.5 \%)$ & $217(50.5 \%)$ \\
\hline Age & & 14 \\
\hline$<30$ years & 10 & 94 \\
\hline 1 -50 years & 72 & 50 \\
\hline $1-60$ years & 70 & 55 \\
\hline$<0$ years & 48 & \\
\hline Level of education & & 92 \\
\hline No formal education & 102 & 44 \\
\hline$<12$ th grade (secondary school) & 33 & 49 \\
\hline Graduate & 59 & 22 \\
\hline Post-graduate & 9 & \\
\hline
\end{tabular}

\section{TABLE 1: Baseline characteristics of the study population}

More than half the participants in our sample did not know the difference between obese and overweight $(\mathrm{n}=220$ [52.8\%]). Of the 265 participants who knew what their ideal body weight should be 221 (83.4\%) knew how to measure it. High-calorie intake and lack of exercise were considered to be causes of obesity by a majority ( $\mathrm{n}=264$ [63.3\%] and $\mathrm{n}=260$ [62.4\%], respectively) (Table 2). 


\section{Cureus}

Non-obese $(n=261)$

Obese $(n=156)$

Do you know the difference between obesity and overweight?

Yes

$140(53.6 \%)$

$80(51.3 \%)$

Do you know the normal blood glucose level?

Yes

$174(66.7 \%)$

$91(58.3 \%)$

Do you know the ideal body weight? And how to measure it?

Yes/Yes

$102(39.1 \%)$

$66(42.3 \%)$

Yes/No

$59(22.6 \%)$

No/Yes

$29(11.1 \%)$

$71(27.2 \%)$

$(15.5 \%)$

No/No

$90(34.5 \%)$

167 (64.0\%)

$73(46.8 \%)$

Slow metabolism

$163(62.5 \%)$

$81(31.0 \%)$

$22(8.4 \%)$

$9(3.4 \%)$

None of the above

of obesity?

What do you think are the risk factors for development of obesity?

Diabetes mellitus

$119(45.6 \%)$

$88(33.7 \%)$

$98(37.5 \%)$

$150(57.5 \%)$

$95(36.4 \%)$

$20(7.7 \%)$
$97(62.2 \%)$

$97(62.2 \%)$

$47(3.1 \%)$

$11(7.1 \%)$

$3(1.9 \%)$

$97(62.2 \%)$

$99(63.5 \%)$

$55(35.3 \%)$

$93(59.6 \%)$

$65(41.7 \%)$

$10(6.4 \%)$

\section{TABLE 2: T2DM patients regarding obesity}

T2DM, type 2 diabetes mellitus

It was found that more obese participants were willing to reduce their weight ( $\mathrm{n}=86$ [55.1\%]) than non-obese participants ( $\mathrm{n}=126$ [48.3\%]) (Table 3). Among those who were willing to lose weight, this was mostly due to a wish to avoid further complications of obesity $(n=155$ [73.1\%]) and also due to peer/family pressures $(n=124$ [58.5\%]). Moreover, more obese $(n=68$ [43.6\%]) than non-obese participants $(n=87$ [33.3\%]) were willing to consult a doctor to help them reduce weight. 


\section{Cureus}

Non-obese $(n=261)$

Obese $(n=156)$

Are you willing to reduce your weight?

Yes

$126(48.3 \%)$

$86(55.1 \%)$

If yes, then kindly select one or more of the following:

Due to peer/family pressure

$55(21.1 \%)$

$69(44.2 \%)$

Avoid further complications

$80(30.7 \%)$

$60(23.0 \%)$

$75(48.1 \%)$

To do daily chores more efficiently

$18(6.9 \%)$

$48(30.8 \%)$

$29(18.6 \%)$

Are you willing to consult a doctor to reduce your weight?

Yes

$87(33.3 \%)$

$68(43.6 \%)$

Do you think overweight people should try to lose their weight?

Yes

$213(81.6 \%)$

$121(77.6 \%)$

How important do you think it is for an obese person with diabetes to lose weight?

Very Important

$202(77.4 \%)$

$134(85.9 \%)$

No need to lose weight

$30(11.5 \%)$

$14(9.0 \%)$

Diabetes and obesity are not related

$26(10.0 \%)$

$8(5.1 \%)$

Do you think having proper knowledge of your condition and treatment can help you reach a controllable state?

Yes

$192(73.6 \%)$

$99(63.5 \%)$

TABLE 3: Behavior of obese and non-obese T2DM patients regarding obesity

T2DM, type 2 diabetes mellitus

A greater percentage of obese $(n=72[46.2 \%])$ than non-obese patients $(n=57$ [21.8\%]) reported multiple previous attempts at losing weight. Participants had adopted various strategies to reduce weight, of which increasing exercise $(n=242$ [85.8\%]) and healthy eating $(n=162$ [57.4\%]) were most popular. Eating habits of patients, i.e., number of meals per day and diet composition, are shown in Figures 1, 2, respectively.

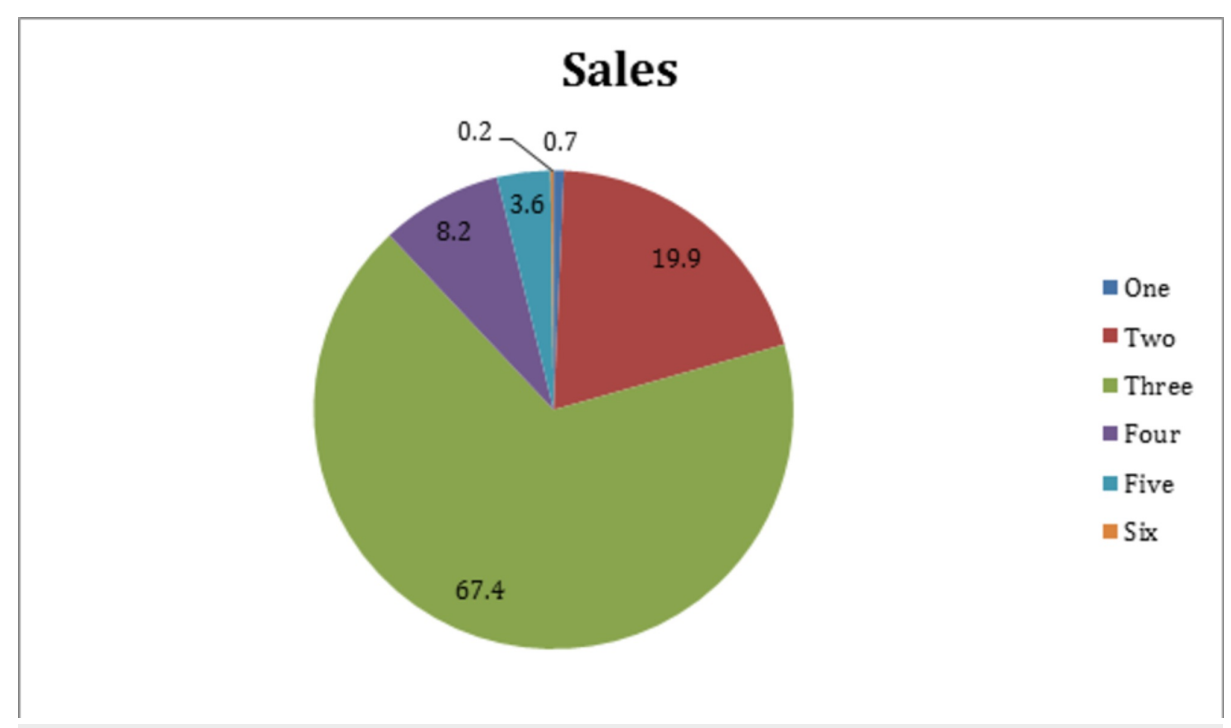

FIGURE 1: Number of meals per day taken by study participants 


\section{Cureus}

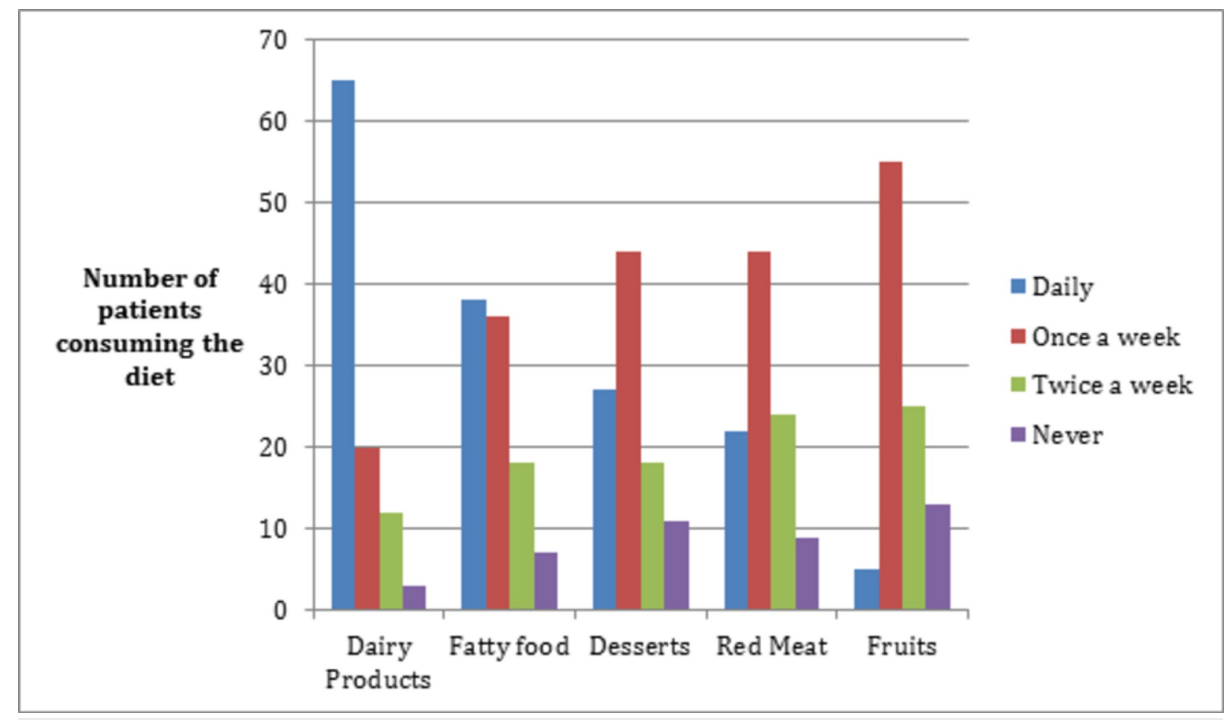

FIGURE 2: Diet composition of study participants

A greater proportion of obese participants exercised daily $(n=71$ [45.5\%]) or had followed a special diet $(n=65$ [41.7\%]) as compared to non-obese ones. Tables 4,5 show the self-care practices of T2DM patients regarding obesity.

\begin{tabular}{|c|c|c|}
\hline & Non-obese $(n=261)$ & Obese $(n=156)$ \\
\hline \multicolumn{3}{|c|}{ Have you ever tried to lose weight in the past? } \\
\hline Yes, many times & $57(21.8 \%)$ & $72(46.2 \%)$ \\
\hline Yes, occasionally & $98(37.5 \%)$ & $55(35.3 \%)$ \\
\hline Never tried & $106(40.6 \%)$ & $29(17.6 \%)$ \\
\hline \multicolumn{3}{|c|}{ If yes, which of the following options have you followed to reduce your weight? } \\
\hline Exercise & $137(52.5 \%)$ & $105(67.3 \%)$ \\
\hline Weight-reducing medication & $31(11.9 \%)$ & $32(20.5 \%)$ \\
\hline Avoiding meals & $69(26.4 \%)$ & 49 (31.4\%) \\
\hline Eating healthy/reducing calorie intake & $100(38.3 \%)$ & $62(39.7 \%)$ \\
\hline \multicolumn{3}{|c|}{ If you said yes to exercise, how often do you exercise? } \\
\hline Daily & $85(32.6 \%)$ & $71(45.5 \%)$ \\
\hline Few times a week & $39(15.0 \%)$ & $27(17.3 \%)$ \\
\hline Few times a month & $13(4.9 \%)$ & $7(4.5 \%)$ \\
\hline \multicolumn{3}{|c|}{ Have you ever been on a diet in an attempt to lose weight? } \\
\hline Yes & $91(34.9 \%)$ & $65(41.7 \%)$ \\
\hline
\end{tabular}

TABLE 4: Practices of obese and non-obese T2DM patients regarding obesity

T2DM, type 2 diabetes mellitus 


\section{Cureus}

\begin{tabular}{|c|c|c|}
\hline & Non-obese $(n=261)$ & Obese $(n=156)$ \\
\hline \multicolumn{3}{|c|}{ How often do you check your blood pressure? } \\
\hline Daily & $28(10.7 \%)$ & 24 (15.4\%) \\
\hline Alternate days & $40(15.3 \%)$ & $21(13.5 \%)$ \\
\hline Twice a week & $49(18.8 \%)$ & $41(26.3 \%)$ \\
\hline Once a week & $71(27.2 \%)$ & 29 (18.6\%) \\
\hline Undocumented & $63(24.1)$ & $41(26.3 \%)$ \\
\hline \multicolumn{3}{|c|}{ How often do you check your blood glucose level? } \\
\hline Daily & $39(14.9 \%)$ & $25(16.0 \%)$ \\
\hline Alternate days & $41(15.7 \%)$ & $31(19.9 \%)$ \\
\hline Twice a week & $49(18.8 \%)$ & $41(26.3 \%)$ \\
\hline Once a week & $71(27.2 \%)$ & $29(18.6 \%)$ \\
\hline Undocumented & $61(24.4 \%)$ & $30(19.2 \%)$ \\
\hline \multicolumn{3}{|c|}{ How often do you check your weight? } \\
\hline Daily & $23(8.8 \%)$ & $34(21.8 \%)$ \\
\hline Alternate days & 20 (7.7\%) & $4(2.6 \%)$ \\
\hline Twice a week & $24(9.2 \%)$ & $25(16.0 \%)$ \\
\hline Once a week & $55(21.1 \%)$ & $32(20.5 \%)$ \\
\hline Undocumented & $139(55.6 \%)$ & $61(39.1 \%)$ \\
\hline
\end{tabular}

\section{TABLE 5: Self-monitoring practices of obese and non-obese T2DM patients}

T2DM, type 2 diabetes mellitus

\section{Discussion}

Obesity among T2DM patients is an alarming issue rising steadily worldwide and needs to be promptly addressed with efficient measures to reduce its economic burden [10]. A study carried out recently showed that being overweight also increases the risk of having cardiovascular and coronary diseases in a diabetic patient [11]. To deal with this issue, there is a need to educate people with T2DM about obesity and body weight reducing measures as patient education influences their health practices [12]. In our study, the majority of diabetics had a family history of obesity (129 [30.9\%]) and hyper-cholesterolemia (134 [32.2\%]) as proven by many types of researches that the fat-mass gene has a strong association with diabetes [13].

In this study, a considerable proportion of participants $(n=220$ [52.8\%]) were unaware of the difference between overweight and obese or about how body weight is measured. This could be since in Pakistan, not every household has a weighing instrument as it is considered an unimportant resource to have, and gyms and places where they are available are unfortunately less popular. This is also reflected in the lack of consistency in weight self-monitoring practices among our participants. Many patients in our study were not regularly monitoring their blood pressure, weight, or blood sugar levels, underscoring the importance of the routine availability of appropriate instruments. Having a weighing machine is as important as having a glucometer in every household with T2DM patients since obesity can increase the risk of developing T2DM complications. Furthermore, clinicians should perceive the need for guidance, medication referral, and advice for weight loss regimens to be able to treat diabetes in their obese patients [14].

The lack of knowledge regarding ideal body weight in this study was surprisingly more profound as compared with a study carried out on newly diagnosed patients in Ghana. However, a satisfactory understanding of weight measurement techniques was found in patients from Ghana [15]. The majority of our patients knew that increased calorie intake (264 [63.3\%]) and lack of exercise (260 [62.4\%]) were risk factors for obesity, as also shown by studies carried out in Bangladesh [12], Ghana [15], and South Africa [16]. 
motivated by both health and social reasons. This could be due to health-related complications already faced by these patients, and a wish to fit in a society where body-shaming is highly prevalent [17]. Unfortunately, only $43.6 \%$ ( $n=68$ ) of obese T2DM patients in our study shared a positive attitude toward consulting their physician for weight-loss counseling, making it imperative for physicians to initiate the discussion about the impact of obesity on the general health of T2DM patients [18].

More obese patients were seen to monitor their blood glucose (157 [37.6\%]) and blood pressure (156 [37.4\%]) levels daily as compared to non-obese ones, possibly due to an understanding that they were at higher risk of heart disease and hypertension than non-obese T2DM patients. In Pakistan, three meals are typically consumed in a day, and fried oily food and dairy products are part of the normal diet regimen. This dietary pattern is consistent with our study findings and a previous study conducted in Pakistan in Aga Khan Hospital Karachi [19]. The popular trend of only "eating out" in Pakistan further makes it challenging for T2DM patients to avoid high-calorie foods [20].

According to a study carried out in Malaysia [21], most diabetic patients showed a positive attitude toward making lifestyle changes; however, they failed to implement them. Another study conducted in Pakistan similarly found that although T2DM patients had profound knowledge about their disease, they failed to apply their knowledge to change their behavior [22]. This highlights the need for public health initiatives that go beyond increasing health awareness and motivate and guide patients on how to make sustainable changes to their diet and physical activity routine.

There have been many successfully executed lifestyle modification programs, such as the U.S. Diabetes Prevention Program (US DPP) and Finnish Diabetes Prevention Program, which provide their participants with weekly guidelines on ways to reduce weight and eat healthily [13,23-25]. Based on these models, similar campaigns can and should be developed in Pakistan too given its current burden of these two chronic illnesses.

Besides large-scale efforts to increase public awareness, physicians also have a critical role in addressing barriers to weight loss among T2DM patients and the need to provide patients with pragmatic guidelines and support on this issue. Physicians should further make appropriate referrals to nutritionists, physical therapists, and bariatric surgery, as needed.

\section{Conclusions}

This study might aid in the application of diabetic education programs, giving more stress on elder and younger groups of patients and fortify the patients to have more connection with concerning physicians so that complications at the early stage of the disease could be prevented.

\section{Additional Information \\ Disclosures}

Human subjects: Consent was obtained by all participants in this study. Animal subjects: All authors have confirmed that this study did not involve animal subjects or tissue. Conflicts of interest: In compliance with the ICMJE uniform disclosure form, all authors declare the following: Payment/services info: All authors have declared that no financial support was received from any organization for the submitted work. Financial relationships: All authors have declared that they have no financial relationships at present or within the previous three years with any organizations that might have an interest in the submitted work. Other relationships: All authors have declared that there are no other relationships or activities that could appear to have influenced the submitted work.

\section{References}

1. World Health Organization: The Asia-Pacific Perspective: Redefining Obesity and Its Treatment . Health Communications Australia, Sydney; 2000.

2. Boffetta P, McLerran D, Chen Y, et al.: Body mass index and diabetes in Asia: a cross-sectional pooled analysis of 900,000 individuals in the Asia cohort consortium. PLoS ONE. 2011, 6:19930. 10.1371/journal.pone.0019930

3. Connolly V, Unwin N, Sherriff P, Bilous R, Kelly W: Diabetes prevalence and socioeconomic status: a population based study showing increased prevalence of type 2 diabetes mellitus in deprived areas. J Epidemiol Community Health. 2000, 54:173-177. 10.1136/jech.54.3.173

4. Jafar TH, Chaturvedi N, Pappas G: Prevalence of overweight and obesity and their association with hypertension and diabetes mellitus in an Indo-Asian population. CMAJ. 2006, 175:1071-1077. 10.1503/cmaj.060464

5. Witkowski TH: Food marketing and obesity in developing countries: analysis, ethics, and public policy . J Macromarket. 2007, 27:126-137. 10.1177/0276146707300076

6. Akhter O, Fiazuddin F, Shaheryar A, et al.: Central adiposity is significantly higher in female compared to male in Pakistani type 2 diabetes mellitus patients. Indian J Endocrinol Metab. 2015, 19:72-76. 10.4103/2230-8210.131767

7. Wang S, Ma W, Yuan Z, Wang SM, Yi X, Jia H, Xue F: Association between obesity indices and type 2 diabetes mellitus among middle-aged and elderly people in Jinan, China: a cross-sectional study. BMJ Open. 
2016, 6:012742. 10.1136/bmjopen-2016-012742

8. Henry RR, Wallace P, Olefsky JM: Effects of weight loss on mechanisms of hyperglycemia in obese noninsulin-dependent diabetes mellitus. Diabetes. 1986, 35:990-998. 10.2337/diab.35.9.990

9. Obesity and overweight. (2020). Accessed: August 20, 2020: http://www.who.int/mediacentre/factsheets/fs311/en/.

10. Hossain P, Kawar B, El Nahas M: Obesity and diabetes in the developing world--a growing challenge . N Engl J Med. 2007, 973:213-215. 10.1056/NEJMp068177

11. Eeg-Olofsson K, Cederholm J, Nilsson P, Zethelius B, Nunez L, Gudbjörnsdóttir S, Eliasson B: Risk of cardiovascular disease and mortality in overweight and obese patients with type 2 diabetes: an observational study in 13,087 patients. Diabetologia. 2009, 52:65-73. 10.1007/s00125-008-1190-x

12. Saleh F, Mumu SJ, Ara F, Ali L, Hossain S, Ahmed KR: Knowledge, attitude and practice of type 2 diabetic patients regarding obesity: study in a tertiary care hospital in Bangladesh. J Public Health Afr. 2012, 3:8. 10.4081/jphia.2012.e8

13. Wu Y, Ding Y, Tanaka Y, Zhang W: Risk factors contributing to type 2 diabetes and recent advances in the treatment and prevention. Int J Med Sci. 2014, 11:1185-1200. 10.7150/ijms.10001

14. Bramante CT, Lee CJ, Gudzune KA: Treatment of obesity in patients with diabetes . Diabetes Spectr. 2017, 30:237-243. 10.2337/ds17-0030

15. Obirikorang Y, Obirikorang C, Odame Anto E, Acheampong E, Dzah N, Akosah CN, Nsenbah EB: Knowledge and lifestyle-associated prevalence of obesity among newly diagnosed type ii diabetes mellitus patients attending diabetic clinic at Komfo Anokye Teaching Hospital, Kumasi, Ghana: a hospital-based crosssectional study. J Diabetes Res. 2016, 2016:9759241. 10.1155/2016/9759241

16. Roux Ml, Walsh C, Reid M, Raubenheimer J: Diabetes-related knowledge, attitude and practices (KAP) of adult patients with type 2 diabetes mellitus in the Free State province. South Afr J Clin Nutr. 2018, 32: 8390. 10.1080/16070658.2018.1468536

17. emon AR, Masood T, Awan WA, Waqas A: The effectiveness of an incentivized physical activity programme (active student) among female medical students in Pakistan: a randomized controlled trial. J Pak Med Assoc. 2018, 68:1438-1445.

18. Davidson JA: The increasing role of primary care physicians in caring for patients with type 2 diabetes mellitus. Mayo Clin Proc. 2010, 85:3-4. 10.4065/mcp.2010.0466

19. Qidwai W, Azam SI: Knowledge, attitude and practice regarding obesity among patients, at Aga Khan University Hospital, Karachi. J Ayub Med Coll Abbottabad. 2004, 16:32-34.

20. Khan MS, Bawany FI, Mirza A, Hussain M, Khan A, Lashari MN: Frequency and predictors of noncompliance to dietary recommendations among hypertensive patients. J Community Health. 2014, 39:732736. 10.1007/s10900-014-9819-9

21. Praythiesh B: Knowledge attitude and practice about diabetes among patients with diabetes attending medicine OPD of tertiary care hospital at Kulasekharam. Int J Commun Med Pub Health. 2018, 5:10.18203/2394-6040.ijcmph20183824

22. Hawthorne K, Tomlinson S: Pakistani moslems with type 2 diabetes mellitus: effect of sex, literacy skills, known diabetic complications and place of care on diabetic knowledge, reported self-monitoring management and glycaemic control. Diabet Med. 1999, 16:591-597. 10.1046/j.1464-5491.1999.00102.x

23. Knowler WC, Barrett-Connor E, Fowler SE, et al.: Reduction in the incidence of type 2 diabetes with lifestyle intervention or metformin. N Engl J Med. 2002, 346:393-403. 10.1056/NEJMoa012512

24. Tuomilehto J, Lindström J, Eriksson JG, et al.: Prevention of type 2 diabetes mellitus by changes in lifestyle among subjects with impaired glucose tolerance. N Engl J Med. 2001, 344:1343-1350. 10.1056/NEJM200105033441801

25. Bergman M, Buysschaert M, Schwarz PE, Albright A, Narayan KV, Yach D: Diabetes prevention: global health policy and perspectives from the ground. Diabetes Manag (Lond). 2012, 2:309-321. 10.2217/dmt.12.34 